FOOTLIGHTS ON THE BORDER 




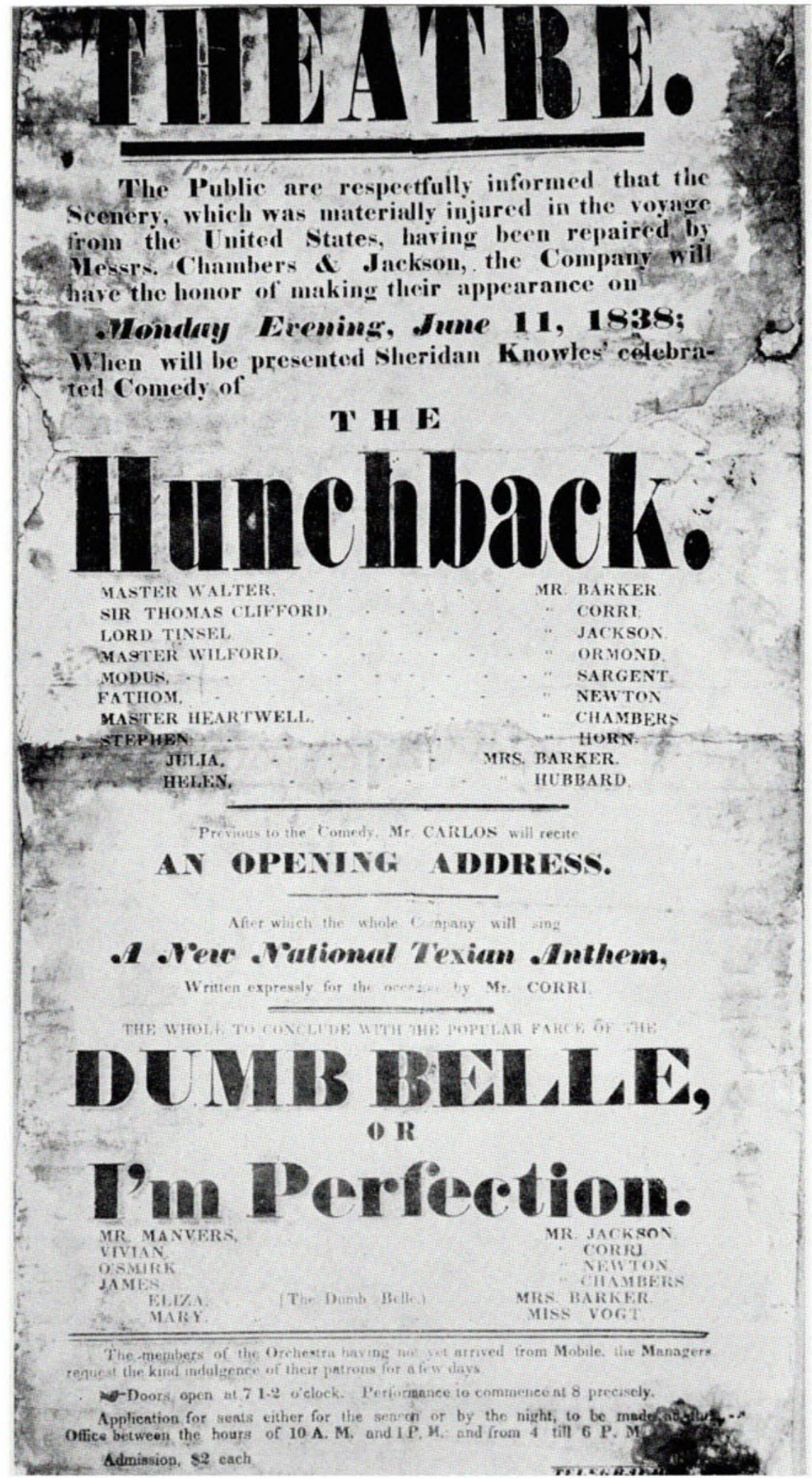


JOSEPH GALLEGLY

FOOTLIGHTS

\section{ON THE BORDER}

THE GALVESTON AND HOUSTON STAGE

BEFORE 1900

1962

MOUTON \& CO • 's-GRAVENHAGE 
(c) Copyright 1962 by Mouton \& Co., Publishers, The Hague, The Netherlands. No part of this book may be translated or reproduced in any form, by print, photoprint, microfilm, or any other means, without written permission from the publishers.

The Frontispiece shows: Playbill of First Dramatic Performance in Texas

(Courtesy of Masonic Grande Lodge of Texas).

Printed in the Netherlands by Mouton \& Co., Printers, The Hague. 
To

Margaret Carmen Gallegly 
